\title{
Heterogeneidade de Preferências e o Uso de Evidências na Câmara dos Deputados ${ }^{1}$
}

Acir Almeida ${ }^{2}$

\section{INTRODUÇÃO}

O movimento que defende que políticas públicas devem se basear na melhor evidência disponível tem grande dificuldade em conciliar essa prescrição técnica com a dimensão inerentemente política do processo decisório democrático. Sobre esta, deve-se reconhecer que sempre haverá debates públicos motivados por diferenças irreconciliáveis, porém legítimas, de interesses ou valores, que o conhecimento científico disponível não será capaz de aplacar. Tais divergências naturalmente incentivam o uso seletivo de evidências, com o objetivo de enviesar decisões, o que é contrário àquela prescrição e, supóe-se, implica políticas públicas de menor eficácia (Parkhurst, 2017). Todavia, uma limitação importante da abordagem das políticas públicas baseadas em evidência (PPBEs) é não oferecer um modelo do processo decisório com base no qual se possa especificar como divergências políticas incentivam o uso estratégico de evidência e como isso afeta decisôes coletivas (Cairney, 2016).

Neste breve artigo, recorro à literatura econômica sobre produção e transmissão de informação para elucidar o uso estratégico de evidências na fase legislativa da produção de políticas públicas. $\mathrm{O}$ fato de incluir múltiplos atores com interesses conflitantes e pouco ou nenhum conhecimento especializado faz do parlamento uma arena especialmente fértil ao uso estratégico de informação. Assim, o objetivo principal do artigo é contribuir para a identificação dos condicionantes políticos da aquisição e do compartilhamento de evidências na arena legislativa.

Para oferecer algum suporte empírico, também apresento resultados preliminares de uma análise original de pareceres emitidos por comissóes da Câmara dos Deputados quanto a iniciativas de política pública do Executivo, no pós-1988. Os achados permitem uma primeira avaliação da qualidade da informação que as comissóes disponibilizam ao plenário e de como ela depende da heterogeneidade de preferências.

\section{COMISSÕES PERMANENTES COMO AGENTES INFORMACIONAIS}

Os congressistas são constantemente chamados a fazer escolhas coletivas acerca de um conjunto muito amplo e diverso de políticas públicas, sobre cujas consequências a maioria deles necessariamente tem pouco ou nenhum conhecimento especializado. Nessas condiçóes, como é possível para o Legislativo produzir decisões bem informadas?

A solução organizacional mais comum consiste em delegar o exame das políticas públicas a comissóes de parlamentares, cada uma com competência exclusiva sobre um ou poucos temas. Isso permite que os membros de cada comissão se concentrem em um subconjunto bem delimitado de questóes relacionadas e tenham mais oportunidade de influenciar a formulação das políticas correspondentes, o que incentiva a especialização parlamentar, tornando mais eficiente a aquisição de informação.

1. DOI: http://dx.doi.org/10.38116/bapi24art10

2. Técnico de planejamento e pesquisa na Diretoria de Estudos e Políticas do Estado, das Instituições e da Democracia (Diest) do Ipea. 
Regimentalmente, assim se organiza o processo legislativo na Câmara dos Deputados. Antes de ser votado em plenário, todo projeto de lei precisa ser encaminhado ao sistema de comissóes permanentes, para exame do mérito e de aspectos formais. Atualmente, existem 25 comissóes (eram dezesseis, em 1989), cada uma composta por poucas dezenas de deputados e com competências definidas segundo áreas temáticas. No caso de o mérito do projeto ser da competência de mais de três comissôes, deve-se constituir comissão especial, composta por pelo menos metade dos titulares das originais. Para produzir o parecer de mérito, o presidente da comissáo designa um relator entre os seus membros, que tem ao seu dispor o órgão de assessoramento técnico-legislativo da Câmara e também pode consultar especialistas externos, do governo ou da sociedade (Brasil, 2016, título II, cap. IV).

No entanto, a frequência elevada com que os deputados aprovam políticas governamentais à margem do sistema de comissóes permanentes - no caso, por meio de medida provisória ou em regime de urgência - depóe contra a visão de que essas arenas são relevantes para subsidiar o plenário com informação especializada. Isso se depreende de explicaçóes do processo legislativo brasileiro que enfatizam: i) as motivaçóes distributivas paroquiais dos deputados (Ames, 1995); ii) os fortes poderes regimentais dos líderes dos partidos, especialmente quando se organizam em uma coalizão majoritária (Figueiredo e Limongi, 1999); e iii) os fortes poderes constitucionais do presidente da República (Pereira e Mueller, 2000). Da primeira perspectiva, conclui-se que as comissóes não têm incentivos para subsidiar o plenário simplesmente porque ele não demanda informaçáo especializada. Das demais, infere-se que, se as comissóes exercem algum papel informacional, ele deve estar subordinado aos interesses da maioria governista ou da sua liderança.

Estudos mais recentes, contudo, indicam a existência de motivaçóes informacionais nas comissões, por exemplo, na seleção de relatores (Santos e Almeida, 2011, cap. 4), no uso da estrutura de assessoramento da Câmara (Santos e Canello, 2016) e na relação com grupos de interesse (Resende, 2019). Também há indícios de que essas motivaçóes condicionam o próprio acionamento do sistema de comissóes permanentes (Almeida, 2018, cap. 5; Santos e Almeida, 2011, cap. 2). Menos claro, no entanto, é se as comissóes são agentes informacionais do plenário ou da maioria governista. Em qualquer caso, importa destacar a existência de fortes indícios de uso seletivo de informação na Câmara. Como concluem Santos e Canello (2016, p. 1.160):

os incentivos informacionais postos ao Legislativo brasileiro não são lineares ou caminham necessariamente de forma progressiva. Não se trata de sempre mais e melhor [informação], em qualquer situação. Ao contrário, a produção endógena de informaçôes se dá num contexto estratégico mais matizado.

\section{USO DE INFORMAÇÃO NA ARENA LEGISLATIVA: TEORIA}

Para especificar o comportamento estratégico das comissóes parlamentares e identificar seus impactos sobre o uso de evidência na arena legislativa, baseio-me em resultados teóricos da literatura econômica sobre produção e transmissão de informação (Beniers e Swank, 2004; Che e Kartik, 2009; Crawford e Sobel, 1982; Krishna e Morgan, 2001). Partindo do pressuposto de que tomadores de decisão não conhecem com certeza as consequências das suas decisóes, essa literatura investiga os incentivos de decisores ou seus agentes para adquirir e compartilhar informação. Por essa perspectiva, o processo legislativo pode ser entendido como um mecanismo que visa à redução da incerteza parlamentar a respeito das consequências de políticas públicas (Krehbiel, 1992). No caso, 
o foco da análise é a informação que as comissões produzem e compartilham com o plenário, mais especificamente, como sua qualidade é afetada por conflitos de interesse.

Seja um processo legislativo com as características especificadas a seguir.

1) O plenário deve escolher uma política pública após observar a recomendação da comissão. Ambos, porém, têm incerteza a respeito da relação entre políticas e seus resultados, sendo que a comissão é mais bem informada e tem a opção de adquirir informação adicional antes de fazer sua recomendação. Preferências são por resultados e tais que se alinham em um eixo unidimensional (por exemplo, a dimensão esquerda-direita), assim como as políticas correspondentes. Os atores conhecem mutuamente suas preferências.

2) Pelo teorema do eleitor mediano, o plenário escolhe a política cujo resultado corresponde à preferência mediana entre os seus membros. A escolha implica perda para todo ator cuja preferência diverge da mediana, táo maior quanto sua divergência. Havendo incerteza, contudo, existe o risco de o resultado observado da política ser diferente do esperado, implicando uma perda adicional, que é crescente na incerteza e igual para todos os atores. A primeira perda, cuja magnitude depende da preferência do ator, chama-se distributiva, pois somente é possível reduzi-la aumentando-se a de outro ator. A segunda, que depende da incerteza e é igual para todos, chama-se informacional.

3) A informação varia segundo a facilidade com que pode ser verificada. Por exemplo, fatos e dados objetivos, especialmente se públicos ou oficiais, são mais fáceis de verificar que percepçóes e opiniôes subjetivas. Quanto mais facilmente verificável a informação, maior a sua qualidade para o decisor. A razão é que informação verificável depende menos das crenças ou preferências da fonte e, logo, é menos manipulável. Podem-se omitir fatos e dados objetivos, mas dificilmente se pode mentir sobre eles (sem ser descoberto). Outra característica importante da informação é que seu custo aumenta com sua qualidade, pois geralmente são necessários mais tempo e esforço para a busca e assimilação de informação verificável.

Para o objetivo limitado deste artigo, destaque-se esta proposição teórica: a qualidade da informação que embasa a recomendação da comissão deve ser crescente na heterogeneidade das preferências (Beniers e Swank, 2004).

Para se entender a lógica subjacente a essa proposição, considere-se inicialmente a inexistência de heterogeneidade, ou seja, uma situação em que a comissão é homogênea e sua preferência (mediana) é igual à do plenário. Como não há divergência entre eles, a comissão não tem motivo para manipular informação, razão pela qual o plenário crê totalmente na recomendação (Crawford e Sobel, 1982). Sua alta credibilidade e a possibilidade de reduzir a perda informacional incentivam a comissão a adquirir mais informação. Porém, como não há perda distributiva, o incentivo não deve ser forte o bastante para que a comissão incorra nos custos mais elevados da coleta de informação de maior qualidade. Logo, quando não há heterogeneidade, a recomendação tende a se basear em informação de menor qualidade (Che e Kartik, 2009).

Para fins de simplificação, sejam três formas de heterogeneidade: divergência entre comissão e plenário; antagonismo entre comissóes; e antagonismo intracomissão. Quanto mais a comissão diverge do plenário, maior sua perda distributiva e, assim, maior seu incentivo para manipular informação, de forma a induzir uma decisão mais próxima da sua preferência. Sabendo disso, o plenário considera a recomendação tão menos crível quanto maior a divergência de interesses. Dada sua menor credibilidade, a única opção da comissão para reduzir sua perda é melhorar a qualidade da informação que utiliza na recomendação. Ou seja, embora a divergência reduza a capacidade da 
comissão de transmitir informação crível, ela gera incentivos para que esta adquira informação de mais qualidade (Che e Kartik, 2009). Portanto, a qualidade da informaçáo deve ser crescente na divergência entre a comissão e o plenário.

Há antagonismo entre duas comissóes quando suas preferências se localizam em lados opostos relativamente à preferência mediana do plenário. Embora ambas tenham incentivos para manipular informação, eles se anulam porque o antagonismo faz com que cada comissão tenha interesse em revelar qualquer informaçáo que a outra deseje manipular, o que torna suas recomendaçóes conjuntamente mais críveis (Krishna e Morgan, 2001). Como a perda distributiva de uma comissão pode ser ainda maior caso a outra consiga influenciar o plenário, ambas têm incentivo adicional para melhorar a qualidade da informaçáo das suas recomendaçóes (Beniers e Swank, 2004). Assim, o antagonismo entre comissôes favorece ainda mais o uso de informação de qualidade, relativamente à situação em que apenas uma comissão diverge do plenário.

Por fim, o antagonismo intracomissão consiste na existência de dois grupos com preferências antagônicas (relativamente à mediana do plenário) na mesma comissão. Nesse caso, se aplica a mesma lógica do antagonismo entre comissóes (Gilligan e Krehbiel, 1989), mas desde que o processo decisório dentro da comissão não cerceie a coleta e o compartilhamento de informação por nenhum grupo, de maneira que sua recomendação contemple as contribuiçóes de ambos os lados. ${ }^{3}$ Logo, o antagonismo intracomissão também é mais conducente ao uso de informação de qualidade.

Em suma, os resultados teóricos levam à conclusão de que a heterogeneidade de preferências favorece a aquisição de informação de qualidade e não é necessariamente ruim para o compartilhamento da informação.

\section{HETEROGENEIDADE DE PREFERÊNCIAS E QUALIDADE DA INFORMAÇÃO NA CÂMARA DOS DEPUTADOS: ANÁLISE EMPÍRICA}

Para avaliar a relação entre heterogeneidade de preferências e a qualidade da informação utilizada pelas comissóes permanentes da Câmara, selecionei uma amostra de projetos de lei de forma a agrupá-los por tipo de heterogeneidade, avaliei a qualidade da informaçáo com base no conteúdo dos pareceres de mérito e, por fim, comparei estatisticamente o nível da qualidade entre os diferentes grupos. Explico esses procedimentos a seguir.

Como não existem dados que permitam avaliar diretamente as preferências políticas das comissóes, selecionei uma amostra não aleatória de projetos de lei com base em critérios que, suponho, distinguem entre os principais tipos de heterogeneidade definidos na seção anterior. Os projetos são os de iniciativa do Executivo, apresentados à Câmara nos anos de 1989 a 2018, com matéria de natureza regulatória e sobre pelo menos um dos seguintes temas: agricultura, indústria, minas e energia, telecomunicaçóes, transportes, defesa do consumidor, meio ambiente e trabalho.

O foco nos projetos governamentais justifica-se por serem politicamente mais relevantes e receberem mais atenção dos deputados. A restrição a matéria regulatória - no caso, que disciplina atividade ou direitos - é em razão do seu maior potencial de conflito de interesses, quando comparada a outras, como as que concedem benefícios ou tratam de aspectos estritamente jurídicos. Por sua

3. Na Câmara dos Deputados, qualquer titular da comissão pode oferecer recomendação alternativa à do parecer vencedor, na forma de voto em separado. 
vez, os temas listados correspondem às competências de oito comissões permanentes ${ }^{4}$ que estão no centro de três debates relevantes e frequentes, que contrapóem, de um lado, a defesa de interesses econômicos setoriais (as cinco primeiras) e, do outro, a proteção de direitos difusos (as três últimas). Com base nesses critérios, e após a exclusão de poucos casos por falta de informação, cheguei a uma amostra total de 86 projetos de lei. ${ }^{5}$

Com o objetivo de criar proxies do grau de heterogeneidade (tal como definida na seção anterior), separei os projetos da amostra em três grupos: 1) com parecer de apenas um tipo de comissáo, ou setorial ou difusa; 2) com pareceres de ambos os tipos; e 3) com parecer de comissáo especial. Respectivamente, os grupos contêm 48, 23 e 15 projetos, sendo o primeiro de controle e os outros dois de casos que supostamente refletem antagonismo entre comissóes e intracomissáo. O pressuposto-chave que orientou o agrupamento é que as preferências em cada comissáo permanente são mais homogêneas e enviesadas (em relação ao plenário) a favor dos interesses da sua área de competência. Assim, se o projeto recebeu pareceres de comissão setorial e de difusa (grupo 2), entáo a matéria provavelmente contrapóe interesse econômico a direitos, situação na qual há antagonismo entre as comissóes. Da mesma forma, se o parecer é de comissão especial (grupo 3) - que, no caso, inclui membros tanto de comissão setorial quanto de difusa -, então as preferências dentro da comissão provavelmente são antagônicas. Por exclusão, o grupo 1 deve incluir os casos com heterogeneidade relativamente menor e, por isso, serve de controle.

Para mensurar a qualidade da informação usada no parecer, construí uma variável ordinal com cinco categorias que expressam (de forma crescente) o nível de qualidade em termos da verificabilidade da informação a respeito dos resultados esperados da política proposta. As categorias e seus respectivos conteúdos estão descritos a seguir.

- Muito alta: dados ou estudos sistemáticos de natureza causal.

- Alta: dados ou estudos sistemáticos de natureza descritiva.

- Moderada: dados pontuais ou estudos de caso.

- Baixa: opinião de especialista, fatos ou exemplos isolados.

- Muito baixa: opinião pessoal.

A categoria que expressa maior qualidade (muito alta) inclui os pareceres que apresentam dados ou estudos sistemáticos sobre os efeitos esperados da política. Na categoria imediatamente inferior (alta) estão os pareceres que contêm dados ou estudos sistemáticos descritivos, geralmente sobre o problema que a política pretende resolver. Os pareceres da categoria intermediária são os que fazem uso apenas pontual de dados ou recorrem a estudos de caso. Na penúltima categoria (baixa) estão os que contêm algum tipo de referência a opinião de especialista, a fatos ou exemplos isolados, sem o uso de dados. Por fim, a categoria que expressa menor qualidade (muito baixa) inclui os pareceres que se baseiam exclusivamente na opinião pessoal do relator.

4. As denominações atuais das comissões são, respectivamente: Comissão de Agricultura, Pecuária, Abastecimento e Desenvolvimento Rural (CAPADR); Comissão de Desenvolvimento Econômico, Indústria, Comércio e Serviços (CDEICS); Comissão de Minas e Energia (CME); Comissão de Ciência e Tecnologia, Comunicação e Informática (CCTCI); Comissão de Viação e Transportes (CVT); Comissão de Defesa do Consumidor (CDC); Comissão de Meio Ambiente e Desenvolvimento Sustentável (CMADS); e Comissão de Trabalho, Administração e Serviço Público (CTASP). 5. A identificação dos projetos de lei e o acesso aos pareceres ocorreram por meio da ferramenta de pesquisas do portal da Câmara dos Deputados, disponível em: <www.camara.leg.br/busca-portal/proposicoes/pesquisa-simplificada>. Sete projetos não entraram na amostra, porque seus pareceres não estão disponíveis on-line. 
A codificação da variável foi feita com base na leitura dos pareceres, pelo próprio autor. No caso dos projetos do grupo 2, que foram examinados pelos dois tipos de comissáo, o valor da variável é o maior entre os atribuídos aos pareceres, o que se justifica pela lógica adversarial da produção da informação.

O gráfico 1 ilustra a distribuição relativa da qualidade da informação nos pareceres emitidos aos projetos da amostra. Com frequência elevada, ela é ou muito baixa $(44,2 \%)$ ou baixa $(34,9 \%)$. Em apenas 7\% dos casos a qualidade é muito alta, com uso de dados ou estudos sistemáticos de natureza causal, e em 5,8\% ela é alta, com dados ou estudos sistemáticos de natureza descritiva. Embora esses achados indiquem uso muito baixo de evidência pelas comissóes permanentes da Câmara, a rigor eles não podem ser generalizados, em razáo da falta de representatividade da amostra.

\section{GRÁFICO 1}

\section{Distribuição da qualidade da informação}

(Em \%)

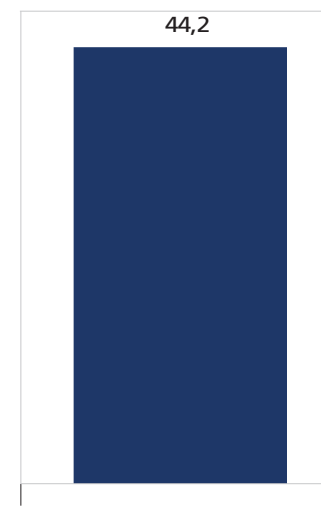

Muito baixa

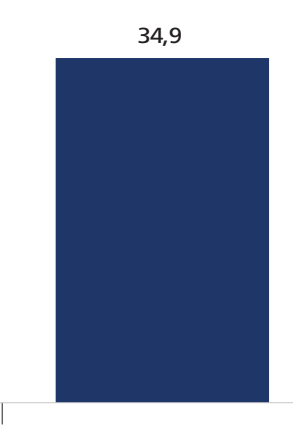

Baixa

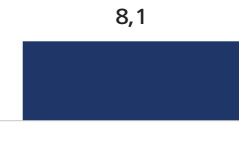

Moderada

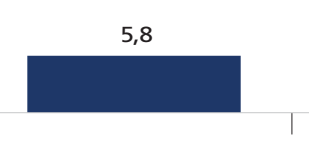

Alta

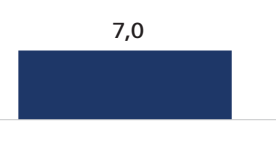

Muito alta

Fonte: Câmara dos Deputados.

Elaboração do autor.

Obs.: Amostra $=86$ casos

Mais importante para o propósito deste artigo é a distribuição da qualidade da informação entre os grupos da amostra. O gráfico 2 ilustra essa relaçáo, com base em estimativas que levam em conta a natureza ordinal daquela variável. ${ }^{6} \mathrm{Da}$ seção anterior, espera-se que a qualidade seja maior nos grupos 2 e 3, mas não necessariamente que difira entre eles. Isso é o que se observa no gráfico e com base em testes estatísticos. Assim, os dados parecem dar apoio à hipótese de que a qualidade da informação é maior quando as preferências são mais heterogêneas - no caso, quando há antagonismo entre comissóes (grupo 2) ou intracomissão (grupo 3).

Para aumentar a confiança nos resultados, considerei dois fatores adicionais. O primeiro é a época em que a comissáo concluiu o parecer. Isso porque a capacidade da estrutura de assessoramento técnico-legislativo da Câmara aumentou ao longo dos pós-1988 (Santos e Canello, 2016), além de a própria disponibilidade de informação técnica naturalmente se ampliar com o tempo. Análises complementares da amostra revelaram que a qualidade da informaçáo apresenta correlaçáo positiva com o tempo decorrido, medido como o número de anos desde janeiro de 1989 até a conclusão do 
parecer, e que a incidência relativa de casos, tanto no grupo 2 quanto no grupo 3, aumentou com o tempo. Esses padróes impóem que se controle pelo tempo decorrido.

\section{GRÁFICO 2}

Distribuição das probabilidades marginais da qualidade da informação, pelos grupos da amostra (Em \%)

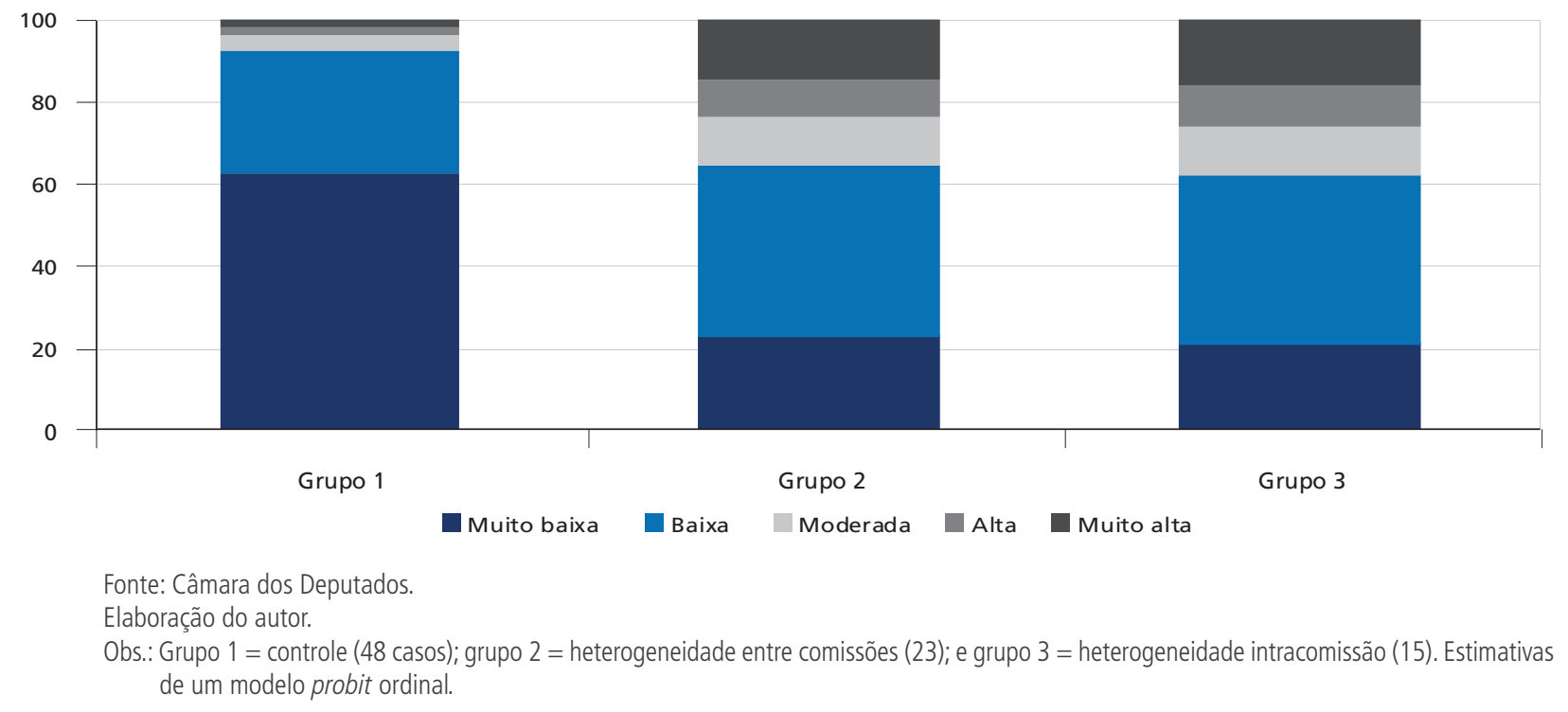

O outro fator é a posição do relator frente ao governo. Com base nas perspectivas que enfatizam a centralidade do conflito entre governo e oposição (Figueiredo e Limongi, 1999; Pereira e Mueller, 2000), pode-se argumentar que relatores oposicionistas têm mais incentivo para coletar informação de qualidade quando o projeto é de iniciativa do governo. Nesse caso, análises adicionais revelaram uma associação positiva, mas não significativa, entre relator de oposição e qualidade da informação, e que a ocorrência desse tipo de relator é maior no grupo 2. Assim, é aconselhável que também se controle pela posição do relator frente ao governo.

O gráfico 3 ilustra os resultados de um modelo de regressão da qualidade da informação como função da heterogeneidade e das duas variáveis de controle. Em razão de a qualidade não diferir entre os grupos 2 e 3, combinei-os em um único. Por sua vez, constatei no grupo 1 uma diferença (não esperada) entre comissóes difusas e setoriais, motivo pelo qual elas estão separadas no modelo. Os pontos no gráfico são a mudança estimada na probabilidade de a qualidade da informação ser muito alta, e as barras de erro são os respectivos intervalos de confiança de $95 \%$.

Relativamente aos pareceres exclusivamente de comissão setorial (o grupo de referência), os dos grupos 2 e 3 têm maior probabilidade de conter informação de qualidade muito alta, sendo a diferença substancial $(0,237)$. Essa probabilidade também é maior em relação aos pareceres exclusivamente de comissão difusa, mas a diferença é bem menos acentuada $(0,237-0,150=0,087)$.

Náo era esperada qualquer diferença sistemática na qualidade da informação entre as comissóes do grupo 1. Contudo, o achado de que a qualidade é maior nos pareceres das comissóes difusas pode ser considerado consistente com a discussão da seção anterior, se for empiricamente plausível supor, por exemplo, que as preferências dessas comissóes se opóem à do governo (o proponente da 
política) com mais frequência que as das comissóes setoriais. De qualquer maneira, o achado em nada prejudica as conclusóes a respeito da relação entre heterogeneidade e qualidade da informação.

GRÁFICO 3

Mudança estimada na probabilidade de a qualidade da informação ser muito alta, por variável

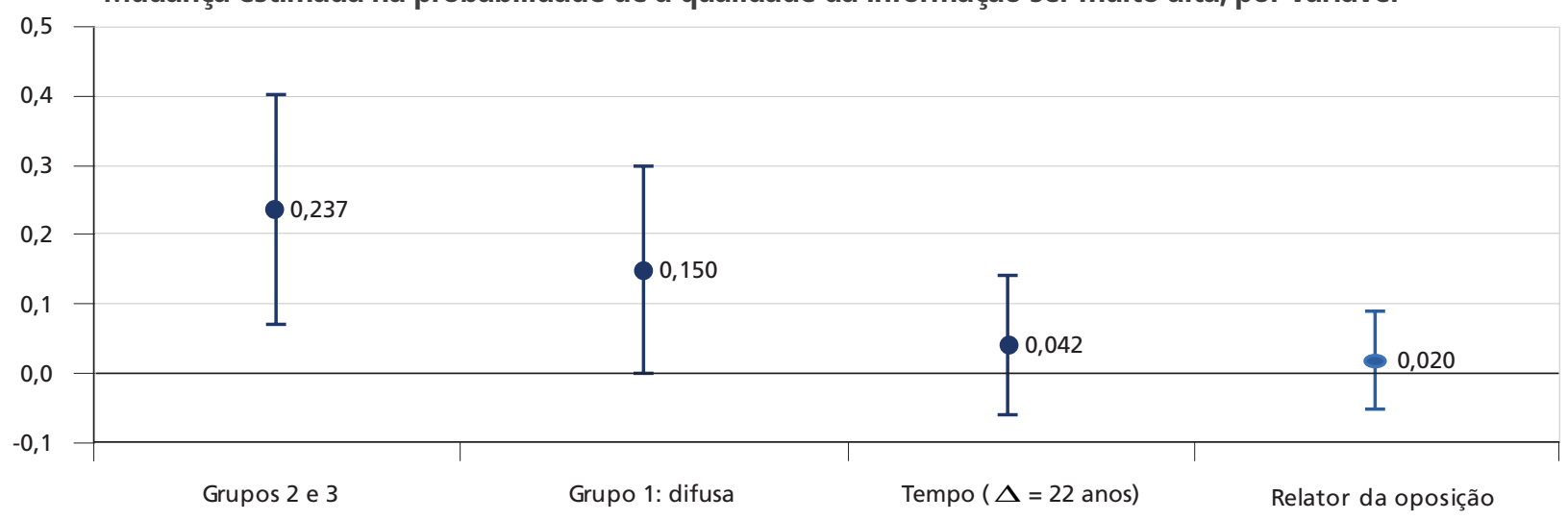

Fonte: Câmara dos Deputados.

Elaboração do autor.

Obs.: Estimativas de um modelo probit ordinal. As barras de erro são os intervalos de confiança de 95\%, com erros-padrão robustos. Amostra $=86$ casos.

Por fim, nem a época da conclusão do parecer nem a posição do relator frente ao governo parece ter relação com a qualidade da informação. Mesmo quando se aumenta o tempo decorrido em 22 anos (três desvios-padrão), a probabilidade muda em apenas 0,042. Por sua vez, a mudança associada à designação de relator da oposição é ainda menor, de 0,020. Nenhum desses valores é significativamente diferente de zero.

Em suma, embora preliminares, os resultados da análise empírica indicam um possível efeito positivo da heterogeneidade de preferências sobre o uso de evidências pelas comissóes permanentes da Câmara dos Deputados.

\section{CONSIDERAÇÕES FINAIS}

É salutar a prescrição de que políticas públicas devem se basear na melhor evidência disponível. A premissa de que decisóes mais bem informadas aumentam o bem-estar geral é consistente com os resultados dos modelos teóricos revisados neste artigo, especificamente no que diz respeito à redução da parcela da perda (informacional) associada à incerteza do decisor. Contudo, é necessário reconhecer que a própria lógica da representação democrática em uma sociedade altamente plural como a brasileira implica um processo decisório permeado de interesses conflitantes e assimetrias informacionais. Nesse contexto, é natural que decisores levem em conta os efeitos distributivos de políticas públicas alternativas e façam uso estratégico de evidências.

Contrariamente ao pessimismo que parece reinar entre os defensores da PPBE, conclui-se deste artigo que há boas razóes para crer que, dependendo da forma como se organiza o processo decisório, o conflito de interesses favorece o uso de evidências na arena legislativa, e que parece ser isso o que ocorre na Câmara dos Deputados.

Não se pretende, assim, sugerir que as decisóes coletivas dos deputados federais sobre políticas relevantes são geralmente bem informadas. Na realidade, o que se deseja destacar, à guisa de conclusão, 
é simplesmente que: é inevitável o uso político de evidências; inexiste contradição necessária entre conflito de interesses e decisóes bem informadas; e, por fim, que a correta identificação das condiçóes e incentivos que favorecem o uso da melhor evidência disponível requer que se compreenda melhor como funciona o processo decisório - sua organizaçáo, seus atores relevantes e suas motivaçóes - e qual o papel da informação para os tomadores de decisão.

\section{REFERÊNCIAS}

ALMEIDA, A. S. Governo presidencial condicionado: delegação e participação legislativa na Câmara dos Deputados. 2018. Tese (Doutorado) - Universidade do Estado do Rio de Janeiro, Rio de Janeiro, 2018.

AMES, B. Electoral strategy under open-list proportional representation. American Journal of Political Science, v. 39, n. 2, p. 406-433, 1995.

BENIERS, K. J.; SWANK, O. H. On the composition of committees. Journal of Law, Economics and Organization, v. 20, n. 2, p. 353-378, 2004.

BRASIL. Câmara dos Deputados. Regimento Interno da Câmara dos Deputados: aprovado pela Resolução nº 17, de 1989, e alterado até a Resolução nº 17, de 2016. Brasília: Ediçôes Câmara, 2016.

CAIRNEY, P. The politics of evidence-based policymaking. London: Springer, 2016.

CHE, Y.; KARTIK, N. Opinions as incentives. Journal of Political Economy, v. 117, n. 5, p. 815-860, 2009.

CRAWFORD, V. P.; SOBEL, J. Strategic information transmission. Econometrica, v. 50, n. 6, p. 1.431-1.451, 1982.

FIGUEIREDO, A. C.; LIMONGI, F. Executivo e Legislativo na nova ordem constitucional. Rio de Janeiro: Editora FGV, 1999.

GILLIGAN, T. W.; KREHBIEL, K. Asymmetric information and legislative rules with a heterogeneous committee. American Journal of Political Science, v. 33, n. 2, p. 459-490, 1989.

KREHBIEL, K. Information and legislative organization. Ann Arbor: University of Michigan Press, 1992.

KRISHNA, V.; MORGAN, J. A model of expertise. Quarterly Journal of Economics, v. 116, n. 2, p. 747-775, 2001.

PARKHURST, J. The politics of evidence: from evidence-based policy to the good governance of evidence. New York: Routledge, 2017.

PEREIRA, C.; MUELLER, B. Uma teoria da preponderância do Poder Executivo: o sistema de comissóes no Legislativo brasileiro. Revista Brasileira de Ciências Sociais, v. 15, n. 43, p. 45-67, 2000. 
RESENDE, C. A. da S. Interesses organizados nas comissões permanentes: percepçóes de grupos de interesse e assessores parlamentares. In: PERLIN, G.; SANTOS, M. L. (Org.). Presidencialismo de coalizão em movimento. Brasília: Ediçôes Câmara, 2019.

SANTOS, F.; ALMEIDA, A. Fundamentos informacionais do presidencialismo de coalizão. Curitiba: Editora Appris, 2011.

SANTOS, F.; CANELLO, J. Comissóes permanentes, estrutura de assessoramento e o problema informacional na Câmara dos Deputados do Brasil. Dados, v. 59, n. 4, p. 1.127-1.168, 2016. 